\title{
ON A MODIFIED FORM OF STABILITY TEST FOR SMOKELESS POWDER AND SIMILAR MATERIALS
}

\author{
By H. C. P. Weber
}

Some time ago an investigation on the stability of nitrocellulose plastics was undertaken at the Bureau of Standards, and the question of the stability of these materials at normal and elevated temperatures was one of the questions studied.

One of the stability tests employed in that investigation seems of sufficient interest to warrant calling attention to it, especially since it does not seem possible to carry the investigation further at present.

The papers to which reference has been made in connection with this subject are tabulated at the end of this paper and will not be cited again in detail.

There is, perhaps, no need for going into details regarding all the various tests proposed. While there are many of them, each having its own particular advantage, only a few are at all generally applied. The reason for adding to their number is that while this test is an explosion test, and therefore simple and rapid, it is in reality a determination of the change of decomposition velocity with rise in temperature and, as such, a measure of stability.

Various investigators have touched upon the influence of the rate of heating on the result, whether it be in the explosion tests or in methods depending on the amount or rate of gas evolution. For this reason the rate of heating in the explosion test is defined within certain limits. The decomposition of nitrocellulose is autocatalytic, and when a certain surrounding temperature is attained, say $135^{\circ} \mathrm{C}$, nearly all samples of nitrocellulose will explode if kept in surroundings of that temperature long enough. The temperature of the decomposing material may be a few or many degrees above $135^{\circ}$. In the investigation of nitrocellulose plastics we have 
repeatedly seen differences of $30^{\circ}$ and $40^{\circ}$ between the temperature of the surroundings and of the sample when the substance went

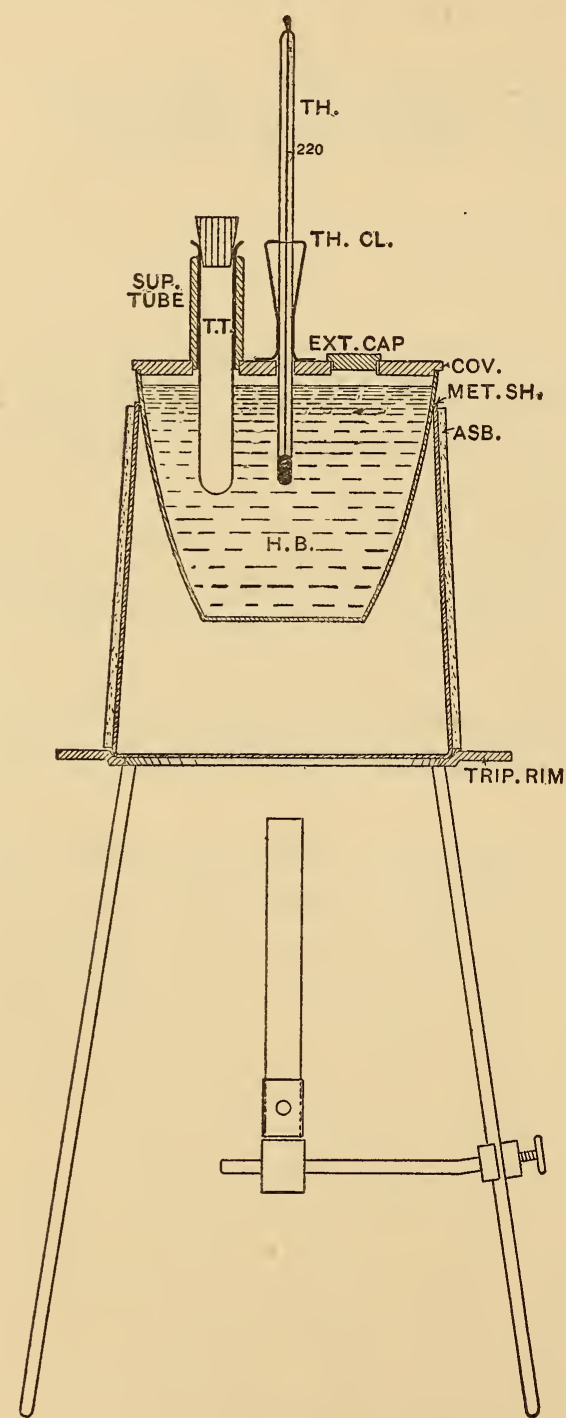

Fig. 1 off. The amount of this difference depends on the mass of the material and its heat conductivity and on the heat conductivity of the system used for test. These factors enter into the German $135^{\circ}$ test as well as into the ordinary high temperature explosion test. In the former the time will vary with the heat insulation; in the latter the explosion temperature will vary with the rate of heating.

The apparatus used for the test is shown in Fig. I. The heating bath consists of a crucible of iron or nickel, about Io $\mathrm{cm}$ in diameter and of approximately the same depth. The cover is of sheet metal, about $3 \mathrm{~mm}$ thick, with a flange that fits snugly into the crucible and projects slightly beyond the rim. One hole through the center of the cover is just large enough to permit the thermometer to pass. Symmetrically distributed around the center of the plate are eight openings $15 \mathrm{~mm}$ in diameter. The heavy metal supporting tubes are about 4 $\mathrm{cm}$ in length and about $\mathrm{I} 2 \mathrm{~mm}$ internal diameter. The lower end of the tube is flanged, so that the tube rests securely on the cover. The test tubes are about $9 \mathrm{~cm}$ long and must be of such diameter 
that they will just slip freely into the supporting tubes. A number of extra caps are provided to cover openings not intended to be used during the test. The heating liquid may be either paraffin, glycerin, or similar inert liquid, which may be heated to $200^{\circ}$ without boiling or fuming strongly. ${ }^{1}$

The test tubes should dip about 4 or $5 \mathrm{~cm}$ into the heated liquid, so that their ends will be at about the center of the heated mass and may readily be removed one at a time and replaced by fresh ones. For each explosion a clean tube should be taken.

The thermometer is supported by a metal clip which rests on the cover, the bulb being on a level with the lower ends of the test tubes. The thermometer used was standardized. Since the mercury thread projected but little above the highly heated zone, the stem correction was found to be negligible. This should be checked with each apparatus and thermometer for the various temperatures when the apparatus is put together.

The heating bath is suspended in a conical piece of sheet metal wrapped with asbestos. The metal shield (Met. Sh.) is cut so that the crucible will hang securely in the upper smaller opening, while its larger end rests in the flanged tripod rim. With this apparatus and a small gas flame it has been easily possible to maintain the temperature constant for 15 or 20 minutes within half a degree. It is most convenient to have the burner set so that there is a tendency for the temperature to fall and to use a small accessory flame momentarily whenever necessary. With a temperature regulator or with electrical heating the ease of manipulation might, no doubt, be increased.

One or two stop watches ${ }^{2}$ complete the equipment. When the apparatus has attained equilibrium at the desired temperature, one or more of the test tubes is loaded by dropping in the sample of powder, the stop watch is started, and a cork is dropped into the mouth of the test tube. The time until the explosion takes place is then noted.

The grains of the 6-pounder smokeless powder are of convenient size to use directly. Powders of larger caliber should be cut into pieces weighing about $0.2 \mathrm{~g}$ each. Each sample of

1 This form of apparatus has been devised by $\mathrm{C}$. E. Waters in connection with work on lubricating oils.

${ }^{2}$ I have found the type of stop watch with two second hands, which may be stopped independently,

the most convenient form. With two of these at least four samples may be observed simultaneously. 
powder was tested at four temperatures, $160^{\circ}, 170^{\circ}, 180^{\circ}$, and $200^{\circ}$. For the present purpose at least three tests were made at each temperature interval and a curve was drawn through the average values.

The following series on powder A shows how closely duplicates may be expected to agree:

$\begin{array}{lrrrrrr}200^{\circ} \mathrm{C} . & 1^{\prime} 44^{\prime \prime} ; & 1^{\prime} 48^{\prime \prime} ; & 1^{\prime} 44^{\prime \prime} ; 1^{\prime} 48^{\prime \prime} ; 1^{\prime} 45^{\prime \prime} & 1^{\prime} 46^{\prime \prime} & \text { Max. Var. } \\ 180^{\circ} & 2^{\prime} 55^{\prime \prime} ; & 3^{\prime} 06^{\prime \prime} ; & 3^{\prime} 10^{\prime \prime} ; & & 3^{\prime} 04^{\prime \prime} & -5 \% \\ 170^{\circ} & 4^{\prime} 17^{\prime \prime} ; & 4^{\prime} 30^{\prime \prime} ; & 4^{\prime} 28^{\prime \prime} & & 4^{\prime} 25^{\prime \prime} & -3 \% \\ 160^{\circ} & 14^{\prime} 20^{\prime \prime} ; \quad 17^{\prime} 40^{\prime \prime} ; 17^{\prime} 34^{\prime \prime} & & 16^{\prime} 36^{\prime \prime} & -14 \%\end{array}$

In general the discrepancies appear to be greater at the lower temperatures. This is to be expected, since the curves given further on show to what extent the influence of small temperature variations is magnified in the region of $160^{\circ}$. Furthermore, the irregularities are more pronounced in the "poor" powders.

The following set shows what can be expected as to reproducibility of the complete curve. The sample used was $L$ and the second test was made one month later than the first. The averages only are given:

\begin{tabular}{|c|c|c|c|c|}
\hline & $200^{\circ} \mathrm{C}$ & $180^{\circ} \mathrm{C}$ & $170^{\circ} \mathrm{C}$ & $160^{\circ} \mathrm{C}$ \\
\hline I & $\begin{array}{ll}1^{\prime} & 31^{\prime \prime} \\
1^{\prime} & 27^{\prime \prime}\end{array}$ & $\begin{array}{ll}2^{\prime} & 18^{\prime \prime} \\
2^{\prime} & 31^{\prime \prime}\end{array}$ & $\begin{array}{ll}3^{\prime} & 39^{\prime \prime} \\
3^{\prime \prime} & 43^{\prime \prime}\end{array}$ & $\begin{array}{ll}7^{\prime} & 11^{\prime \prime} \\
7^{\prime} & 30^{\prime \prime}\end{array}$ \\
\hline
\end{tabular}

The following table and Fig. 2 give the results obtained with Io samples of smokeless powder and two samples of nitrocellulose. The samples were obtained through the Navy Department, and I am indebted to the courtesy of G. W. Patterson, powder expert at Indian Head, for the selection of three classes, good, fair, and poor, and for the description of these samples, which I quote for comparison with the explosion periods:

Nitrocellulose A.- "Specially prepared. Heat test, potassium-iodide starch, at $65^{\circ} .5 \mathrm{C}, 4$ minutes; German test at $\mathrm{I} 35^{\circ} \mathrm{C}, 9$ minutes for litmus red.'

Nitrocellulose B.- "Heat test, potassium-iodide starch, at $650_{5}^{\circ}$ C, 42 minuces. German test at $135^{\circ} \mathrm{C}, 3^{8}$ minutes for litmus red."

Powder Sample A.- "Six-pounder. Diphenylamine as stabilizer. German test at $135^{\circ} \mathrm{C}$, litmus red, 2 hours 35 minutes, explosion 5 hours plus. Surveillance test at $80^{\circ} \mathrm{C}, 87$ days; at $655_{5}^{\circ} \mathrm{C}, 307$ days."

Sample B.- "Medium caliber. Diphenylamine as stabilizer. German test at I $35^{\circ} \mathrm{C}$, litmus red, 2 hours I7 minutes, explosion 5 hours plus. Surveillance test at $65^{\circ} 5^{\circ} \mathrm{C}, 27 \mathrm{I}$ days." 
Sample C.-_" Large caliber. Diphenylamine as stabilizer. German test at $135^{\circ} \mathrm{C}$, litmus red, I hour 25 minutes, explosion 5 hours plus. Surveillance test at $65^{\circ} \cdot 5$ C, 245 ảays plus."

Sample D.- "Large caliber. No stabilizer. Rosaniline as indicator. German test at $\mathrm{I} 35^{\circ} \mathrm{C}$, litmus red, 2 hours, explosion 5 hours plus. Surveillance test at $65^{\circ} 5 \mathrm{C}, 60$ days."

Sample E.- "Medium caliber. No stabilizer. Rosaniline as indicator. German test at $\mathrm{I} 35^{\circ} \mathrm{C}$, litmus red, I hour 35 minutes, explosion 5 hours plus. Surveillance test at $65^{\circ} \cdot 5 \mathrm{C}, 74$ days."

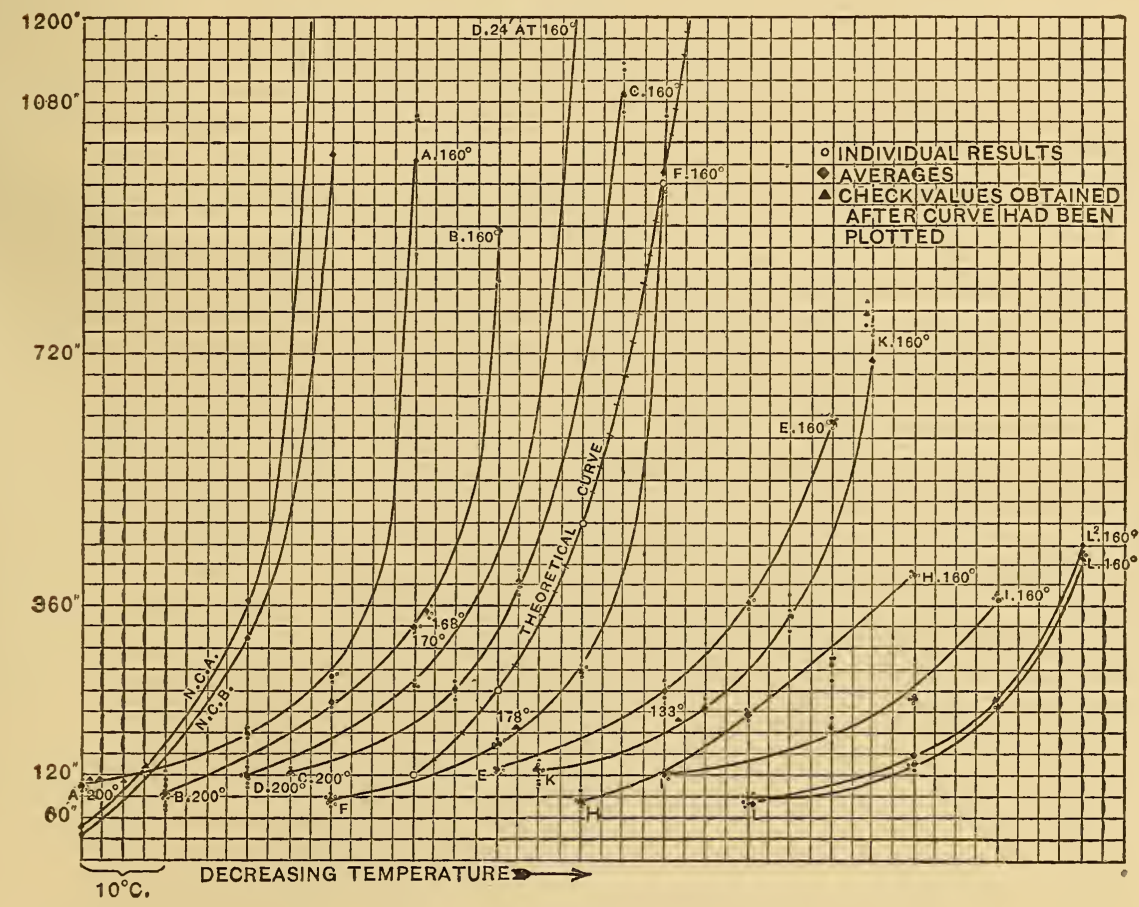

Fig. 2

Sample F.- "Six-pounder. Contains rosaniline and diphenylamine. German test at $135^{\circ} \mathrm{C}$, litmus red, 2 hours 25 minutes, explosion 5 hours plus. Surveillance test at $65^{\circ} 5 \mathrm{C}, 375$ days; at $80^{\circ} \mathrm{C}, 64$ days."

Sample H.- "Manufactured in Igor. When last tested it gave German test at I $35^{\circ}$ C, explosion in 4 I minutes. Surveillance test at 65.5 C (I907), 79 days."

Sample I.- "Manufactured about I9or. When last tested, it gave German test at I $35^{\circ} \mathrm{C}$, explosion in 33 minutes; surveillance test at $65.5^{\circ} \mathrm{C}, 82$ days."

Samples $\mathrm{K}$ and L. - "These are both in very poor condition, giving only one day surveillance test."

The explosion periods obtained on these samples are as follows. The value underscored is the average value. 
Explosion Periods

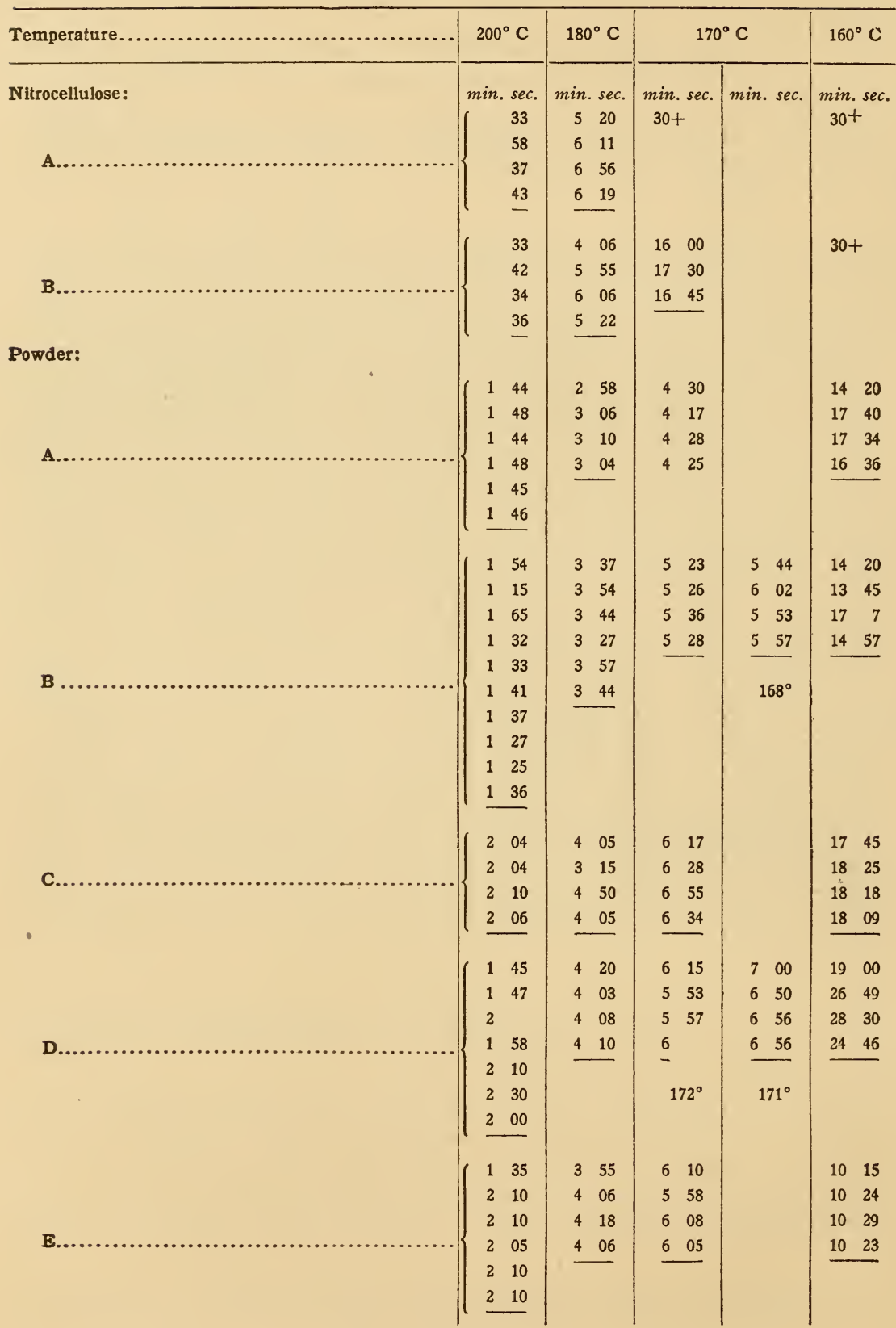


Explosion Periods-Continued

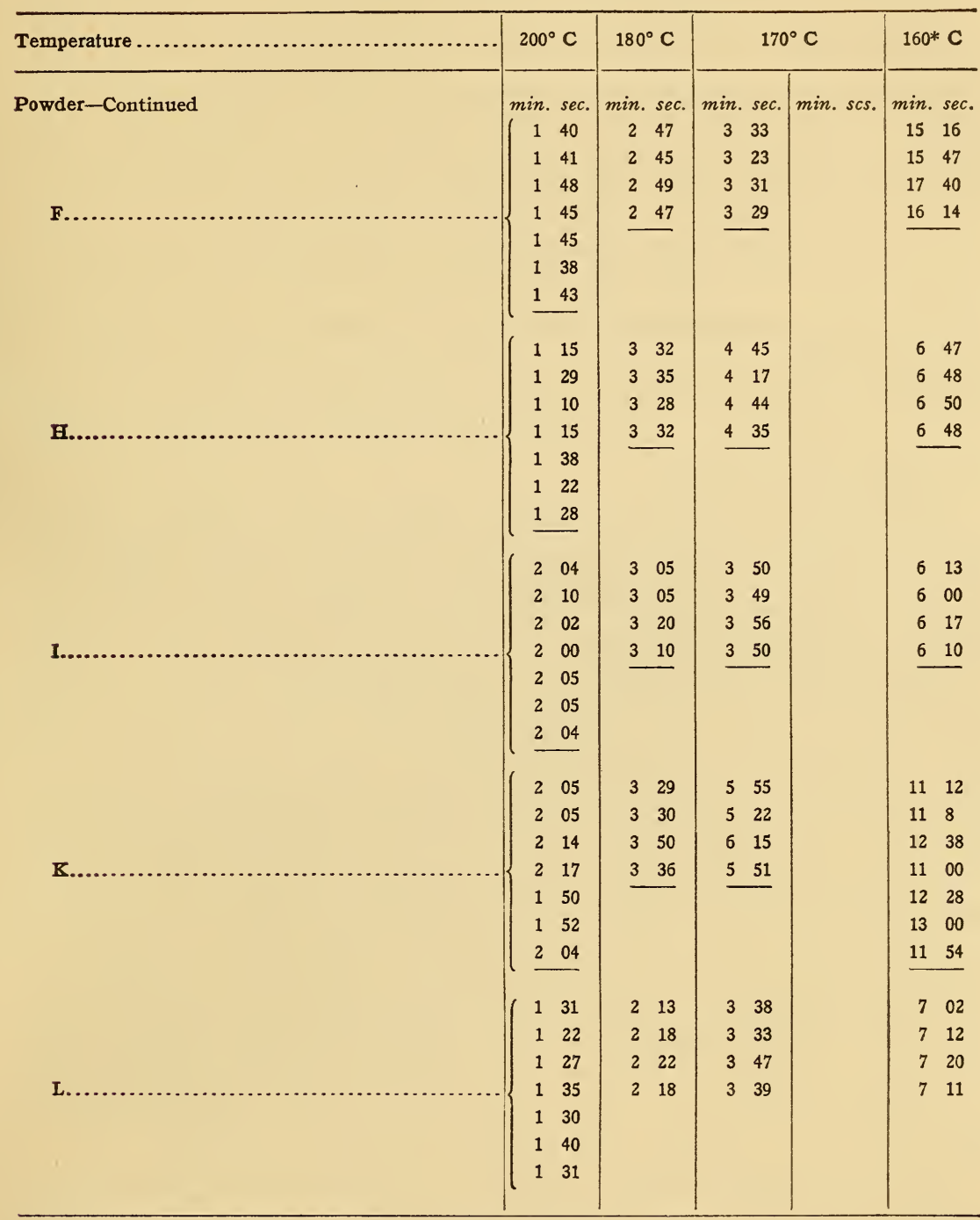

$\mathrm{K}$, at $183^{\circ}, 3-20,3-29$; at $160^{\circ}, 12-43,13-20$ minutes and seconds.

$\mathrm{F}$, at $178^{\circ}, 3-00,3-13$ minutes and seconds.

A, at $199^{\circ}, 1-47$; at $198^{\circ}, 1-53$; at $197^{\circ}, 1-52$; at $195^{\circ}, 1-56$; at $193.5^{\circ}, 2-12$ minutes and seconds.

The curves embodying these results are given in fig. 2. The curve marked "theoretical curve" is obtained on the assumption that the reaction velocity doubles for every $10^{\circ} \mathrm{C}$. While the $82208^{\circ}-\mathrm{I} 3 \longrightarrow 9$ 
curves obtained from the explosion periods are of the same general type, it is apparent that the relation is not so simple as that shown by the "theoretical curve." What influence the stabilizer has upon the direction of the curves it is difficult to say with the data at hand. It does not follow that the stabilizer will affect the explosion test in the same manner as it does the heat test or the surveillance test. The stabilizer, while it removes the products of decomposition, may of itself act as a positive or negative catalyzer. If the decomposition be considered as the dissociation of an ester, the presence of a substance removing the products of decomposition will increase the rate. This has been noticed by Mittasch ${ }^{3}$ for nitrocellulose with various basic additions and has been confirmed by myself in the case of pyroxyline plastics containing zinc oxide.

That the curves do actually represent the stability of the powder with changing temperature and are not accidental is shown by the reproducibility of the various points along the curve, as shown in the table; by the fact that the curve having been determined by four points, determinations made at varying temperatures are found to fall on the curve; and by the fact that the complete curve can be reproduced at widely varying intervals. (See curves $L^{\prime}$ and $L^{\prime \prime}$.) The curves are undoubtedly characteristic for the sample. The deviations for individual points are not large enough to affect the general trend of the curve. What temperatures are chosen must probably be left to individual requirements; $190^{\circ}$ would perhaps be preferable to $200^{\circ}$. At ${ }_{1} 50^{\circ}$ we should have the apparent advantage that the differences between various samples become greater and the disadvantage that the test becomes slower and the results are more subject to accidental influences. The bend of the curve between $180^{\circ} \mathrm{C}$ and $\mathrm{I} 60^{\circ} \mathrm{C}$ is, perhaps, its most characteristic portion.

The curves fall into three distinct groups for the samples tested, corresponding to their general classification of good, fair, and bad. The stable powders have a pronounced bend, while the ratio of explosion periods at $200^{\circ} \mathrm{C}$ and $160^{\circ} \mathrm{C}$ is at least $2: 9$. In the unstable samples this ratio falls as low as $2: 3$, and the points do not fit a smooth curve so well. The curves for the two 
samples of raw nitrocellulose are somewhat peculiar, being much flatter and corresponding more nearly to the theoretical curve.

The powders do not always fall in exactly the same order by this explosion test as they do by the surveillance or the heat test, but I think this is true to the same extent for the $135^{\circ}$ German explosion test and the ones mentioned. This appears by comparison of the customary tests on samples $\mathrm{D}$ and $\mathrm{H}$ :

$\mathrm{D}$, German test $\mathrm{I} 35^{\circ}$ litmus red 2 hours, explosion 5 hours; surveillance 60 .

$\mathrm{H}$, German test; explosion $4 \mathrm{r}$ minutes; surveillance 79 .

From the results given it is evident that one explosion temperature, even if time is considered, does not give much information, while the determination of the characteristic curve does yield definite and specific information.

On account of the complexity of the conditions the test can hardly be expected to tell all that is to be known, but I believe that with sufficient data it may even be made to throw some light on the actual effect of the stabilizer on the natural decomposition velocity of the powder, as distinguished from the length of time before the decomposition products become noticeable.

\section{CONCLUSION}

The proposed method gives more accurate determinations of the explosion temperature than the method of heating with rising temperature.

It gives a better comparison of the relative stability of explosive substances.

The test is in effect a determination of the rate of change of decomposition velocity with change of temperature and is as such characteristic for each sample.

WASHINGTON, June 22, I9I2. 
ASPINWALL:

\section{LITERATURE REFERENCES}

Stability Tests for Smokeless Powder and Nitroexplosives. J. Soc. Chem. Ind., 21, p. 687 .

BERGMANN AND JUNK:

Stability of Nitrocellulose. Zs. angew. Chem., 17, pp. I7, 982, Iо18, I074. CULLEN:

Note on the so-called "Heat Test" for Explosives. J. Soc. Chem. Ind., 20, p. 8. ESCALES:

Stability of Nitrocellulose. Zs. angew. Chem., 18, p. 940.

Methods for Testing Stability of Explosives in Various Countries. Zs. ges. Schiess- und Sprengstoffwesen, 5, pp. 21, 72, 2 ro. Finzr:

Ignition Points of Nitrocellulose and Smokeless Powders. Gazz. Chim. Ital., 39, I, p. 549 .

German Railway Administration:

Tests and Regulations of the. Zs. ges. Schiess- u. Sprengstoffwesen, 4, p. I75. JACQUE:

Causes and Methods of Determining Decomposition of Nitrocellulose. Zs. ges. Schiess- u. Sprengstoffwesen, 1, p. 395.

LUNGE AND BEBIE:

Contributions to the Knowledge of Nitrocellulose. Zs. angew. Chem., 14, pp. $543,56 \mathrm{r}$.

MirTASCH:

Stability of Nitrocellulose. Zs. angew. Chem., 16, pp. I6, 929. OBERMÜLLER:

Mitteil. aus dem Berliner Bezirks-verein, etc. October, I904. See Wilcox, J. Am. Chem. Soc., 30, p. 27 r.

PATTERSON:

Stability Tests of Smokeless Powder. Seventh International Cong. Applied Pleus:

Chem. Explosives, p. 99.

Some Improvements in the Apparatus for the Obermüller Manometer Test. Zs. ges. Schiess- und Sprengstoffwesen, 5, p. I2I.

ROBERTSON: Rubin:

On the Will Test for Nitrocellulose. J. Soc. Chem. Ind., 21, p. 8rg.

Testing Regulations and Black Powder Safety Explosives in England. Zs. ges. Schiess- u. Sprengstoffwesen, 4, p. 2 I.

\section{Saposhnikov:}

Rate of Decomposition of Nitrocellulose and Temperature. Russ. Phys. Chem. Soc., 38, p. I186. 
SNELLING AND ToBIN:

Behavior of Nitroglycerine when Heated. Bureau of Mines, Technical Paper I2; I9I2.

Sy:

Stability of Nitrocellulose. J. Am. Chem. Soc., 25, p. 549; Zs. angew. Chem., 18, p. I824.

Wilcox:

Decomposition Curves of Nitrocellulose. J. Am. Chem. Soc., 30, p. 27 I. WILL:

Stability of Nitrocellulose. J. Soc. Chem. Ind., 20, 602.

Stability of Celluloid. Zs. angew. Chem., 19, p. I386.

ZSCHOKKE:

Testing of Explosives. Zs. ges. Schiess- u. Sprengstoffwesen, 6, p. 24I. 